\title{
Anti-CD22 ADC TRPH-222
}

National Cancer Institute

\section{Source}

National Cancer Institute. Anti-CD22 ADC TRPH-222. NCI Thesaurus. Code C156882.

An antibody-drug conjug ate (ADC) composed of an anti-CD22 humanized monoclonal antibody site-specifically conjug ated to, via formylglycine (FG) residues and a protease insensitive 4AP linker, a cytotoxic microtubule-targeting maytansinoid payload, with potential antineoplastic activity. Upon administration, the monoclonal antibody moiety of TRPH-222 binds to B-cell-specific CD22 receptors and is rapidly internalized, thereby delivering the payload intracellularly. Upon proteolytic cleavage, the maytansinoid payload binds to tubulin, disrupting microtubule assembly/disassembly dynamics, inhibiting both cell division and tumor cell proliferation. CD22, a cell surface sialog lycoprotein, is expressed on mature B-cells and on most malignant B-cells. The site specific and stable conjug ation to the payload allows for a higher drug-to-antibody ratio (DAR) and an enhanced therapeutic index. 